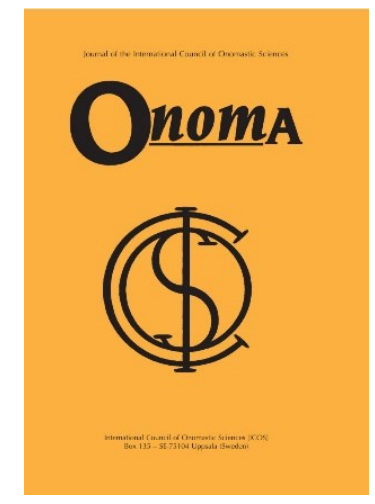

Onoma 50

Journal of the International Council of

Onomastic Sciences

ISSN: 0078-463X; e-ISSN: 1783-1644

Journal homepage: https://onomajournal.org/

\title{
User names of illegal drug vendors on a darknet cryptomarket
}

DOI: $10.34158 /$ ONOMA.50/2015/2

\section{Lasse Hämäläinen}

Finnish Language

FI-00014 University of Helsinki

lasse.j.hamalainen@helsinki.fi

www.researchgate.net/profile/Lasse_Haemaelaeinen

To cite this article: Hämäläinen, Lasse. 2015. User names of illegal drug vendors on a darknet cryptomarket. Onoma 50, 45-71. DOI:

10.34158/ONOMA.50/2015/2

To link to this article: https://doi.org/10.34158/ONOMA.50/2015/2

(C) Onoma and the author.

\section{User names of illegal drug vendors on a darknet cryptomarket}

Abstract: The illegal drug trade has recently found a new route: darknet cryptomarkets. On these Ebay-like marketplaces, located in an anonymous network, drug sellers and buyers from all over the world make deals without meeting each other in person. Drug vendors are known by their user names, and those names could have a huge financial significance for their owners. This study examines the characteristics of those vendor user names and contrasts them to both other types of user names as well as to real-life commercial names. The data for the study were collected from AlphaBay, which was the largest cryptomarket in early 2017.

Many vendors share information of themselves through their user names, referring to their products, home country and whether they work alone or in a group. Names are also used to create various images of vendor's business. Some vendors try to create an image of a normal, legal business by using company and brand name vocabulary or by plagiarising famous real-life brand names. Other vendors, however, appear to even highlight their criminality, referring to illegal activities or well-known 
real-life or fictional drug criminals. Vendor names also include references to the desired effects of drugs and the high quality of products and service. One-third of names are not connected to drugs in any visible way. Overall, vendor names more closely resemble other user names, but they clearly have also been influenced by commercial names.

Keywords: user names, commercial names, darknet, drugs, cryptomarket.

\section{Pseudonymes de trafiquants de drogue sur un cryptomarché du darknet}

Résumé : Le trafic illégal de drogue a récemment trouvé une nouvelle voie: les cryptomarchés du darknet. Sur ces plateformes comparables à eBay et localisées sur un réseau anonyme, des vendeurs et consommateurs de drogue venus des quatre coins du monde font des affaires sans se rencontrer personnellement. Les vendeurs se font connaitre sous des pseudonymes, et ces noms d'utilisateur peuvent avoir un impact financier important pour leur propriétaire. Cette étude examine les caractéristiques des pseudonymes utilisés par les vendeurs de drogue et les compare à d'autres types de noms d'utilisateur en ligne ainsi qu'à des noms commerciaux de la vie réelle. Les données de l'étude ont été collectées sur AlphaBay, le plus large cryptomarché au début de l'année 2017.

Un bon nombre de vendeurs partagent des informations les concernant par le biais de leur pseudonyme : cela peut concerner le produit qu'ils proposent, leur pays d'origine ou bien encore la façon dont ils travaillent, seul ou en groupe. Les noms sont aussi utilisés dans l'optique de créer certaines représentations du vendeur et de son commerce. Certains vendeurs essaient de forger l'image d'un commerce normal et légal en utilisant un vocabulaire onomastique relevant du monde des entreprises et des marques ou en plagiant de célèbres noms de marques de la vie réelle. D'autres vendeurs, en revanche, semblent quant à eux vouloir souligner leur côté criminel, en faisant référence à des activités illégales ou à des trafiquants de drogue réels ou fictionnels bien connus. Les noms de vendeur peuvent également inclure des références aux effets désirés des stupéfiants et à la qualité des produits et du service. Un tiers des noms ne sont pas liés à la drogue de quelque manière visible que ce soit. Dans l'ensemble, les noms de vendeur ressemblent de près aux autres noms d'utilisateur en ligne, mais ils sont aussi clairement influencés par les noms commerciaux.

Mots-clés : Noms d'utilisateur, noms commerciaux, darknet, drogue, cryptomarché.

\section{Benutzernamen illegaler rogenhändler auf einem Darknet-Marktplatz}

Zusammenfassung: Der illegale Drogenhandel hat in letzter Zeit neue Handelswege gefunden: die Kryptomarktplätze des Darknets. Auf diesen Ebay ähnlichen Markplätzen, die sich in anonymen Netzwerken befinden, handeln Drogenhändler und Käufer weltweit ohne sich persönlich zu treffen. Die Drogenverkäufer sind über ihre Benutzernamen bekannt, ihre Namen könnten für ihre Träger daher eine große finanzielle Bedeutung haben. Diese Studie untersucht die Charakteristiken der von Verkäufern gewählten Benutzernamen und vergleicht sie sowohl mit anderen Typen von Benutzernamen als auch mit Markennamen der realen Wirtschaftswelt. Die Daten für die Studie wurden zu Beginn des Jahres 2017 auf AlphaBay, dem größten existierenden Kryptomarkt, gesammelt.

Viele Verkäufer vermitteln sie selbst betreffende Informationen über ihren Benutzernamen, indem sie auf ihre Produkte, ihr Heimatland und darauf verweisen, ob sie alleine oder im Team agieren. Namen werden auch dazu verwendet, ein 
gewisses Image über die eigene Geschäftstätigkeit zu vermitteln. Einige Verkäufer versuchen das Image eines normalen, legalen Unternehmens zu erschaffen, indem sie Wirtschafts- und Markenvokabular oder bekannte Markennamen plagiatsmäßig nutzen. Andere Verkäufer dagegen scheinen ihre Kriminalität geradezu zu betonen, indem sie auf illegale Aktivitäten oder bekannte Drogenkriminelle des echten Lebens oder der Fiktion verweisen. Verkäufernamen enthalten auch Verweise auf die gewünschten Wirkungen der Drogen und die hohe Qualität ihrer Waren und Dienstleistungen. Ein Drittel der Namen sind auf keinerlei Weise mit Drogen verbunden. Insgesamt ähneln Verkäufernamen mehr anderen Benutzernamen, aber sie sind auch durch Warennamen beeinflusst.

Schlüsselbegriffe: Benutzernamen, Warennamen, Darknet, Drogen, Kryptomarkt. 


\title{
User names of illegal drug vendors on a darknet cryptomarket
}

\author{
LASSE HÄMÄLÄINEN
}

\section{Introduction}

During the last decade, the trade of illegal drugs has been moving from the streets to online. Deals are not made on the internet but on the darknet, an anonymous non-public network. Even though the darknet is used for many legal or even gallant purposes, such as human-rights defending and campaigning, dissident activism and whistleblowing (Dingledine et al. 2004; Bartlett 2014: 2), it mostly makes the headlines due to its illegal activities. The darknet contains many websites called cryptomarkets which offer platforms for selling and buying illicit items such as drugs, firearms and counterfeit money. They essentially work in the same manner as consumer-to-consumer marketplaces on the public internet, such as Ebay ${ }^{1}$. Users from all over the world can add their sales advertisements freely. When a buyer makes an order, the seller sends the items through the postal service. The buyer may then rate the quality of the product, duration of shipment, customer communication as well as other aspects of the service in the marketplace. Payments are made in virtual currencies, most often Bitcoins.

The main reason that the drug business is moving online is anonymity. The darknet is mostly used via Tor Browser ${ }^{2}$, which includes an advanced procedure for concealing the identity of its user. For this reason, law enforcement officials have difficulty ascertaining who runs or uses cryptomarkets. The fact that the drug seller and buyer do not know each other also decreases the threat of violence when compared to traditional in-person dealing (Barratt, Ferris \& Winstock 2016). Open global trade also has other benefits. Vendors can raise their revenues by delivering the products throughout the world, directly to the customers without using middlemen. On the other hand, the competition of several similar products on the website forces vendors to sell better quality products at a lower price (Caudevilla et al. 2016; Aldridge, Stevens \& Barratt 2017), which of course benefits the customers.

1 The juxtaposition between Ebay and cryptomarkets has been debated in academic context (for example, see Barratt 2012; Aldridge \& Décary-Hétu 2014), but for people with little previous knowledge about cryptomarkets, it may demonstrate the phenomenon rather well. www.torproject.org (accessed 2018-04-24). 
Why should onomasticians be interested in this phenomenon? In order to use a cryptomarket, both vendors and buyers need to register a user account, including a user name, in the service. This user name is important for the vendors for at least two reasons. Firstly, when customers are satisfied, they are likely to purchase from the same vendor again (Décary-Hétu \& Quessy-Doré 2017). For security reasons, however, cryptomarkets usually do not preserve the data from previous transactions. This means that using services from the same vendor requires remembering the vendor's name. Secondly, anonymous online trade is primarily based on trust (Tzanetakis et al. 2016). The buyer needs to trust that the vendor sends the product, that its quality is good and that it is packed so stealthily that it will pass any possible custom checks. But how can anyone trust someone when they know nothing about them and there is no legal authority to monitor the actions? This problem has been tried to solve with several trust systems provided by cryptomarkets (Décary-Hétu \& Leppänen 2013; Nurmi et al. 2017), but those systems are not completely without problems (e.g. Hardy \& Nordgaard 2016: 521, 533). For this reason, it is extremely important for the vendor to create an image and an identity of a trustworthy seller. This is a challenging task, however, as the vendors cannot reveal any specific personal information without exposing themselves to law enforcement interference. Consequently, the vendor has to experiment with images and associations. The user name plays a major role in this. It serves as the label of the vendor's identity, the first information that a customer will learn about the vendor.

The aim of this study is to provide an overview of the user names that drug vendors adopt on a darknet cryptomarket. Four main research questions are proposed:

1) What are the structure and orthography of vendor names?

2) What information do names provide about vendors?

3) What type of images do vendors create in their names?

4) Are vendors' names closer to other user names or real-life commercial names?

The first three questions are answered in three separate analysis sections (2.1-2.3). The fourth question is addressed throughout the article, and the findings are summarised in the conclusions. Nonetheless, I will begin by discussing some academic publications related to the current study and by introducing the methods used to collect and analyse the data.

\subsection{Related work}

User names have been a subject of scholarly studies since the early years of the internet, with Bechar-Israeli (1995) as the first contribution. However, a greater number of studies have been published only during the 2010s. Scholars 
have focused on several types of web services, such as chats (Ecker 2011; Hassa 2012), discussion forums (Stommel 2007; Hämäläinen 2019), dating services (Visakko 2015: 134-143) and gaming communities (Kelley 2012; Hämäläinen 2013; 2019; Kokkinakis et al. 2016). Katarzyna Aleksiejuk (2014; $2016 \mathrm{a}$; 2016b; 2017) has made a concerted effort to define the place of user names in the field of onomastics and has reviewed the various terminology adopted for personal names in online environments. The overall picture of user name characteristics, however, has remained unclear. The datasets in previous studies have been rather small (excluding Kokkinakis et al. 2016) and the methods of analysis have been predominantly qualitative. In many studies, user names have been a tool used to examine other phenomena, rather than being the actual focus of the study. For instance, Stommel (2007) and Kelley (2012) utilize user-name data to examine users' identities, while Cornetto \& Nowak (2006) and Kokkinakis et al. (2016) endeavour to obtain the biographical information of users. This means that many general features of user names, such as structure and orthography, have been relatively unexamined.

As mentioned in the introduction, the user names on cryptomarkets potentially have a huge financial significance for their owners. It is therefore also relevant to compare these user names to commercial names. This field of onomastics has been developing rapidly during this century. For example, the series of Names in the Economy symposia have been organised since 2006. Sjöblom (2016) offers a brief overview of this area, and a more elaborate description can be found in Ainiala et al. (2012: 210-254). Commercial names include many categories and subcategories of names, such as names of companies, brands and products. The user names of drug vendors should be compared to names of companies, as they are both units designed to deliver certain services for a profit. In this area, perhaps the most relevant counterpart is the study by Frank Nuessel (2017) on the names of legal marijuana dispensaries in Colorado.

The darknet and cryptomarkets remain relatively new phenomena. One of the first and perhaps the most known cryptomarket, Silk Road, began operating in February 2011 (Christin 2013). Scholars in several fields of science have been quick to react, as some notable research has appeared only a few years later (for example, see Christin 2013; Martin 2014; van Hout \& Bingham 2014). Since then, the volume of new studies has been rapidly increasing. A work that is particularly worth mentioning is volume 35 of The International Journal of Drug Policy with the theme "Drug Cryptomarkets", which analyses the subject mainly from social and societal points of view (see Barratt \& Aldridge 2016 for an overview of the volume). However, the current study is, at least to my knowledge, the first linguistic approach to cryptomarkets and their culture.

Online environments typically change rapidly. This applies even more to the darknet than the internet. The lifespan of a cryptomarket is usually short; 
most of them have been running only a few years at most before law enforcement have managed to close them or the administrator has decided to do so. Due to this quick tempo of changes, all the necessary information for this study cannot be found from scholarly sources. In these cases, my primary source of information has been Deepdotweb.com, a website dedicated to sharing up-to-date news and information on the darknet. Many previous works on cryptomarkets (see for example Dolliver \& Kenney 2016; Martin \& Christin 2016; Tzanetakis et al. 2016) refer to its articles as well, so it can probably be regarded as a relatively trustworthy source.

The darknet and cryptomarkets are referred to with several terms in both scholarly studies and non-academic contexts. The terminology is examined perhaps most comprehensively by Barratt \& Aldridge (2016). The anonymous network itself has been referred to as the darknet or dark net, deepweb or deep web, hidden web, or Tor network. The public internet, on the contrary, is called clearweb or clear web (Aldridge \& Askew 2017). Darknet marketplaces have been rather solidly referred to as cryptomarkets since the study published by Martin (2014). This term refers to the high-level encryption that is used to protect user privacy on the marketplaces, and as this is the primary motivation for using these marketplaces, the term cryptomarket can be regarded as being descriptive. The users who sell products on cryptomarkets are usually called vendors, both in the scholarly literature and on the cryptomarkets themselves (Barratt \& Aldridge 2016; Dolliver \& Kenney 2016). As a consequence, their user names can be shortened to vendor names. The present study adopts the terms darknet, clearweb, cryptomarket, vendor and vendor name.

\subsection{Data and method}

The data for the current study were collected from a cryptomarket called AlphaBay $^{3}$, which was established in 2014 (Deepdotweb 2015a). When the data were collected in April 2017, AlphaBay was the largest cryptomarket (Deepdotweb 2017a; see also van Buskirk et al. 2016b: 5-8). At that time, there were approximately 330,000 sales advertisements, with more than two-thirds of them $(225,000)$ related to drugs and chemicals. The number of users was not publicly available, but the AlphaBay staff reported reaching 200,000 registered users in late 2015 (Deepdotweb 2015b), and in 2017, the count was claimed to be approximately 400,000 (Alphabaymarket.com 2017). AlphaBay was closed by a global law enforcement operation in July 2017 (Deepdotweb 2017c). This shutdown caused very few problems for the completion of this

3 The name is most likely derived from eBay and refers to the similar features of these two marketplaces (see footnote 1). 
study. When the shutdown occurred, almost all of the necessary information had been collected. I would have liked to check some details, but they are insignificant in the big picture.

Both vendors and buyers on AlphaBay had to create user names. The data of this study include only the user names of the vendors. Vendor names were visible on the marketplace while the buyers' names were not, and therefore collecting vendor names was much easier. Moreover, vendor names have a much greater economic importance for their owners, and they can therefore be regarded as a more interesting research subject.

The data were collected from the sales advertisements of three substance categories: ecstasy, heroin and LSD. The three substances are somewhat different in terms of their production and psychoactive effects, and thus it can be presumed that they must be marketed in different ways. The data include all the vendor names I have found in the sales advertisements (Figure 1). This does not mean all the vendors of the three substances, as the AlphaBay search function displayed only the first 650 results of each search. In many cases, this is only a small portion of all the advertisements in a product category. For example, there were more than 16,000 advertisements for ecstasy tablets at the time of my data collection. However, many vendors had dozens or even hundreds of advertisements with different types of products (such as different types of ecstasy tablets) or a different number of items (such as 10 or 100 ecstasy tablets). Thus, by combining results of several searches, I have attempted to collect a sample that represents vendor names on AlphaBay rather well. The data contain 762 vendor names, of which 363 sold ecstasy, 283 LSD and 233 heroin. Eighty-five vendors sold two of these substances and 16 vendors all the three substances.

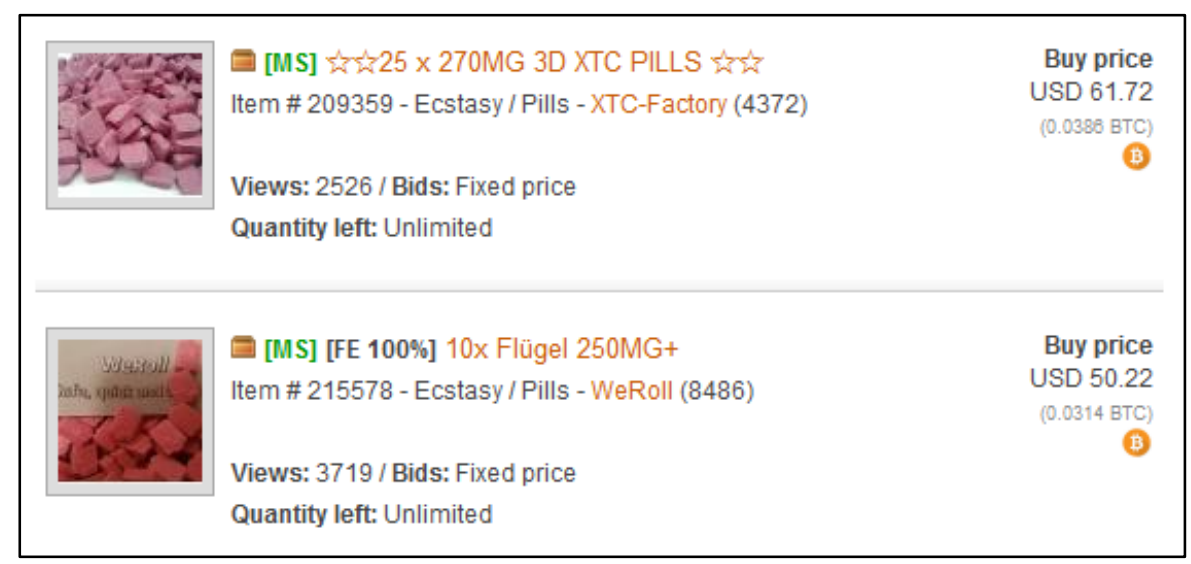

Figure 1: Ecstasy sales advertisements on AlphaBay.

The vendor's user name (XTC-Factory, WeRoll) is shown on the second line of each item.

Names can be examined from two different perspectives: that of a name giver and that of the language community (Ainiala et al. 2012: 35; Sjöblom 
2006: 59-61). This analysis adopts the latter method. This means that the data are analysed without interviewing the vendors on the backgrounds of their names. This choice was made for both theoretical and practical reasons. When analysing commercial names, I find the customer's point of view more relevant. The reception and success of a name depends not on the vendor's motive for selecting that name, but how the customers see and interpret it. Moreover, drug vendors often reject interview requests, because interviews are seldom beneficial for them, but revealing any personal information may expose them to law enforcement officials. For instance, the most successful and wellknown Finnish online drug vendor, known by the name Douppikauppa 'dope store', became famous for granting interviews to the Finnish media (one of them is translated into English, see Deepdotweb 2016). The publicity and the information given in interviews, nevertheless, were reasons to alert law enforcement officials and to help them arrest Douppikauppa employees in April 2016. For this reason, a sample collected by interviewing vendors would presumably have remained considerably smaller than the one used in this article. As a consequence, most cryptomarket researchers have only collected data that are available without interviews, or interviewed only drug buyers who as minor offenders face a considerably smaller threat and are therefore more willing to participate (Barratt \& Aldridge 2016: 3-4). The few studies conducted by interviewing drug vendors (van Hout \& Bingham 2014; Buxton \& Bingham 2015; Ormsby 2016) have had rather small samples or have required a substantial amount of work in their data collection.

As a new, rapidly changing environment of research, cryptomarkets challenge many traditional ethical guidelines in scientific research. These are too complex questions to be reviewed comprehensively here; they have been addressed in a few previous studies, perhaps most elaborately by Martin \& Christin (2016). A brief note on data collection and usage may, however, be appropriate to ease any possible reader concerns. All the data collected for this research were available half-openly; using the AlphaBay market required registration for the service, but all the sales advertisements and vendor user profiles were available for all the registered users. Registration on the website was not illegal, was free of charge and did not require revealing any personal information (such as an email address). This type of data is regarded as being essentially public (Christin 2013: 221); anyone, including law enforcement agencies, could have collected a dataset similar to the one used in this study. Consequently, the data collection and use pose no additional risk of being arrested for the marketplace operators (Martin \& Christin 2016: 88), and therefore they should have no reason to hold negative opinions on this study or myself. Considering those factors, using the data introduced in this chapter should fulfil scientific ethical criteria. 


\section{Analysis}

\subsection{Structure and orthography}

The structures of user names are usually rather short and simple. This is probably due to the character limits imposed on user names on many websites (see also Aleksiejuk 2017: 176-177). I did not manage to determine what that limit was for AlphaBay, but apparently it was not the most restrictive; the longest user name in the data contains 27 characters (Your_Friendly_Neighborhood_), which is more than in any of my previous studies (Hämäläinen 2013; 2019). On average, the vendor names in the data contain 11.0 characters, which is also a significantly higher number than the averages reported in my previous datasets. ${ }^{4}$

In the data, 109 names $(14.3 \%)$ contain numbers. This count is rather small; in the gaming community Playforia, for instance, $35 \%$ of the user names contain numbers (Hämäläinen 2019). The main reason for the moderate use of numbers might be that they are not very popular user name elements, particularly because they render names more difficult to remember (Hämäläinen 2013: 223228). AlphaBay was somewhat smaller community than Playforia is, so unique user names could be created more easily, in many cases without using numbers as differentiating elements. Numbers in vendor names often include shared connotations (area51UFO, evilsorcerer666, LaredoKing_247, ledzep420), or replace a letter with a similar shape (DutchCandyShOp, Tr4derJo3) or a word with similar pronunciation (Bud2UK, drugs 4 sell) ${ }^{5}$ Some numbers appear to refer to certain years, possibly the user's year of birth ${ }^{6}$ (cerealkkiller1979, tommyjones 1990) or the year of registration on AlphaBay (ACAB2016, dutchfastest2017). The majority of the numbers that occur in vendor names, however, do not seem to convey any particular meaning (123killer, cxvipe7, Gman19635, sizzle650, Sinatra2, sobob777, tantrikom39).

The use of special characters in user names is limited in different ways on different websites. Some websites allow practically all the characters available on the standard keyboard, while some websites allow only a few different special characters. AlphaBay belonged to the latter group, with the

4 In the data analysed in Hämäläinen (2019), user names in a gaming community Playforia average 8.3 characters, names in a soccer-themed discussion forum FutisForum 8.3 characters, and names in a fanfiction community Finfanfun 8.0 characters. The length of the names in FutisForum and Finfanfun can be 1-80 characters, so the character limit cannot explain why vendor names are longer than other user names.

5 Area 51 refers to an area in Nevada, U.S., which appears in several fictional contexts; 666 is called 'the number of the Beast' in the Book of Revelation; 247 refers to 24 hours of a day and 7 days of a week, practically meaning 'all the time'; 420 refers to the international cannabis day, April 20. 0 should be read as $o$ (Dutch candy shop), 4 as $a$ and 3 as $e$ (trader Joe), 2 as to (bud to UK) and 4 as for (drugs for sell).

6 For example, Kokkinakis et al. (2016: 607-608) suggest that in the League of Legends player community, sets of two or four digits conventionally refer to a player's year of birth. 
$\operatorname{dot}($.$) , hyphen (-)$ and underscore $\left(_{-}\right)$being the only available special characters in user names. Special characters are found in 132 names $(17.3 \%)$ in the data, most often between words (Made.in.Germany, The-Solution, this_fading_light). They are very rare either at the beginning or at the end of the name (Gustavo_, -DutchDynamite-). This is a noticeable difference in comparison to other types of websites, which include special characters in various positions to make user names unique (Hämäläinen 2019). Like numbers, special characters could make names more difficult to remember correctly (Hämäläinen 2013: 227), which may explain their not being used very often on AlphaBay.

In most Western cultures, proper names begin with a capital letter. User names are an exception to this practice. In many online communities, even the majority of user names begin with a lowercase letter (see, for example, Hämäläinen 2019). The AlphaBay data, however, contain 487 vendor names $(63.9 \%)$ that begin with a capital letter. The other words in a name also begin with a capital letter rather frequently. One reason for that is to make word boundaries easier to distinguish because spaces cannot be used (DrMantisTobogganMD, TheDrugsCo, PrayForTheSun cf. besafeandenjoy, deepintheheartof7, theoriginaldragoncove). However, capital letters are often also used when special characters occur between the words (Acid_Monster, Cosmic_Consciousness, The-Mad-Hatter). This can be understood as an influence from commercial names. Ainiala et al. (2012: 225) note that capital letters are used especially to distinguish the functional parts of company names and to draw customers' attention (see also Aleksiejuk 2017: 174; 178-179). For the other positions in vendor names (Ace13R3Vk7, PeRfecT_ProDuctS, StarDockGaLiX), however, capital letters are used rather rarely. Only 37 names $(4.9 \%$ of the data) are completely capitalised (DONALD-TRUMP, MAX-HAVELAAR, TESCOEXPRESS). This may be somewhat surprising, because capitalisation was used abundantly in AlphaBay sales advertisements (as in the upper advertisement in Figure 1). Nevertheless, some informants of my previous studies (Hämäläinen 2013) have told that they find excessive and continuous capitalisation to be inelegant or even irritating, so perhaps the choice by vendors not to capitalise their names is actually clever.

\subsection{What information do vendors share?}

As stated in the introduction, the online trade of illicit drugs is based on a buyer's trust in a vendor. In addition to sending orders as promised, the best way for a vendor to earn a buyer's trust is to reveal something about him- or herself. In this section, I review three categories of information that the vendors tend to share in their names: product, country of origin and number of employees. 


\subsubsection{Product}

In the data, there are 124 user names (16.3\%) that include a direct reference to vendors' products. Sixty-four of them refer to drugs in general. This can be achieved by several different words. The most common of them is obviously drug, which appears in 31 vendor names (Harddrugsspecialist, theDrugFederation, UniversalDrugs). However, the names also include references to pharmacy and medicine (11 names, such as CanadianPharmaceuticals, LaFarmacia, MedicinalMary, Medibank), chemistry and chemicals (10 names, such as ChemExpress, ChemicalAllstars, ChemicalEmotions) or narcotics and dopes (9 names, such as Narcotique, thenarcostoreUK, Dopelord, and hqdopestore). The word choice may serve both ideological and marketing purposes. The references to pharmacy suggest that the substances are not only used recreationally but also to treat mental and even physical health, which may make purchasing them feel more legitimate. The same strategy can be observed in the names of legal marijuana dispensaries, which often use the words wellness, health, medical and medicine (Nuessel 2017: 118). The words chemical and chemistry, on the other hand, imply that in addition to attempts to change one's state of mind, they can be used for many other purposes, such as chemical experiments. The words dope and doping have a negative tone in a sports context, but among the drug users, they are somewhat neutral slang words for psychoactive substances and their use. Slang words also occur in marijuana dispensary names (ibid.). The word narcotics, on the other hand, refers to the addictive features of drugs (cf. narcomania) and has a negative tone, which may explain its somewhat moderate use in vendor names.

Regardless of the precise word choice, vendor names that refer to drugs serve an informative function. They reveal that the vendor's branch of business is production and trafficking drugs. However, a pertinent question is whether this information is necessary. Approximately two-thirds of all sales advertisements on AlphaBay were categorised as drugs, which makes it plausible that an average AlphaBay vendor sells drugs. Consequently, the function of these names is perhaps integrating rather than informative (about the functions of commercial names, see Ainiala et al. 2012: 243-244).

Sixty vendor names refer to a certain type of drug. Of these, 28 refer to ecstasy (MDMASTER, MollyBoys, XTC-Factory), heroin (HeroinUSA, Quality_Opiates, Smack_) or LSD (AcidAnonymous, LSDirect, Sandoz1943), which are the 3 substances involved in the data collection. ${ }^{7}$ The remaining 32 names in this group refer to various other substances (crystalmethinc, methadone, morphin,

7 MDMA is the active ingredient in ecstasy; molly is a slang word for MDMA or ecstasy; $X T C$ is an informal abbreviation of ecstasy (see Figure 1). Opiate is a pharmacological term for substances derived from opium (such as heroin); smack is a commonly used slang word for heroin. Acid is a common slang word for LSD; Sandoz1943 refers to time and setting of LSD discovery (the year 1943, Sandoz, a Swiss pharmaceutical company). 
TheKetamineClub) but especially to cannabis (Canadabis, GoddessOfGanja, YourWeed) and psychedelics (DMT-lovestore, PsychedelicSavior, shroomdude). ${ }^{8}$ Names that refer to a certain substance are probably meant to create an image that the vendor is specialised in selling this particular drug or at least has some special know-how concerning it. Yet according to van Buskirk et al. (2016a), approximately half of the cryptomarket vendors sell more than one type of drug. This means that the image of specialisation cannot be extended to more than one of these substances. For example, the name XTC-Factory may be attractive for an ecstasy buyer but perhaps not as appealing to an LSD buyer, even though the vendor actually sold both substances. As a result, it may not be surprising that vendor names referring to a particular substance are not very frequent in the data.

\subsubsection{Country of origin}

Vendor names often include a reference to vendor's home country. This is because the country of origin is one of the key factors that affect the buyer's selection of a product. If the buyer and the vendor are located in same country, shipping of the product is far safer because the item does not have to pass custom checks. The country of origin may also imply the quality of the product, which is an important factor when selecting a vendor (see Bancroft \& Reid 2016).

In the data, 146 names $(19.2 \%)$ contain a direct reference to the vendor's home country. Their distribution by country is shown in Table 1. As we can see, the superior leader in the table is the Netherlands, which is hardly surprising. The Netherlands is known as a high-volume producer and trafficker of illicit drugs, especially synthetic drugs such as ecstasy and amphetamine (e.g. EMCDDA 2013). Kruithof et al. (2016: 74, 99) have observed that the Netherlands have by far the largest number of cryptomarket drug vendors and revenues per capita. Another country that stands out from the list with respect to its population is Australia. The Australian customs system is one of the strictest in the world, which makes importing drugs exceptionally difficult. Therefore, Australian vendors can ask higher prices than others. Also worth mentioning is that China is mentioned in only one vendor name (HongKongPost), even though it is recognised as one of the top five vendor countries in the study by van Buskirk et al. (2016a). This may be because most Chinese drugs go to international consumers rather than domestic ones, so Chinese vendors have no domestic vendor advantage (ibid.: 21). It may also be that unlike the Netherlands, China does not have a reputation of drug culture and high quality of drugs which would benefit marketing their products.

8 Ganja and weed are slang words for cannabis and shroom for psilocybin mushrooms. 
Table 1: References to the country of shipping

\begin{tabular}{|r|c|c|}
\hline Country & Count & $\mathbf{\%}$ \\
\hline Netherlands & 64 & 43.8 \\
\hline Great Britain & 20 & 13.7 \\
\hline Australia & 16 & 11.0 \\
\hline Germany & 15 & 10.3 \\
\hline United States & 6 & 4.1 \\
\hline Canada & 6 & 4.1 \\
\hline France & 5 & 3.4 \\
\hline Switzerland & 5 & 3.4 \\
\hline Other & 9 & 6.2 \\
\hline Altogether & $\mathbf{1 4 6}$ & $\mathbf{1 0 0}$ \\
\hline
\end{tabular}

Reference to a country can be made in a few different ways. The most usual methods for vendor names are to incorporate the name of the country (DrugsFromHolland, HongKongPost, ITALIA), its inhabitants (canadianforger, DUTCHRABBIT2, German-Masters), or the country code (DarknetFR, DiscounterNL, high_as_fxck_GER, Ukcartel). Eleven Dutch vendors refer to their capital, Amsterdam, (OldAmsterdamm, AmsterdamLiquidXno1, AmsterdamQuality), whereas 10 Australian vendors use their country's nickname, $\mathrm{Oz}$ (gogogoz, OzLSD, OZ-TEAM, ozziedirect), perhaps owing to its shortness.

Most of the vendor names in the data occur in English. AlphaBay was an international marketplace, and English serves as the most common lingua franca on the darknet as well as on the internet. Therefore, using some language other than English can be an indirect reference to a vendor's home country. This is used predominantly by the vendors in the German-speaking area (such as GeileTeile, Hund, Kaufland, Untergrund). However, the local features in vendor names do not always refer to the country of origin. For instance, owners of the names Santa.Muerte and ChivasRegal, which refer to a Mexican folklore deity and a Scotch whisky, are both located in the Netherlands.

\subsubsection{Single agent or a group}

The user names on the clearweb are usually owned by a single individual. However, producing and distributing illegal drugs often requires the cooperation of several people, at least on a professional level and on an extensive scale. Expertise is needed in multiple areas, such as chemistry, smuggling, packaging, contacts and marketing. For these reasons, it can be presumed that many AlphaBay vendor accounts were owned by a group of people. Eileen Ormsby (2016: 63) has reached the same conclusion after interviewing Silk Road drug vendors.

The data contain 71 names $(9.3 \%)$ that imply that the vendor account is run by a group of people. Thirty-two of them use vocabulary that refer to a group of agents, such as a club, collective, connection, crew, flock, syndicate, team and united 
(CLUBMNL, tscollective, AmsterdamConnection, TheTechnoCrew, partyflocknl, karmasyndicate, goldengloryteam, NinjasUnited), while the other 39 simply use the plural form in their names (BritishKnights, FastGermanDealers, frenchmen, StealthMasters, SuccessMachines, theprofessionals, TheUntouchables, yeah-theboys). In real life, many customers would avoid doing business with drug gangs due to the threat of violence. When the deals are made online, the parties do not know each other and often are also separated by great distances, so this threat is massively reduced. Actually, the implication that the vendor shop is owned by a group of agents may even have a positive impact on marketing. A group of people is more likely to have expertise in several areas of a business and therefore be able to monitor product quality, pack the items stealthily, send them regularly and maintain contact with the customers successfully.

There are also many vendor names that refer to a single agent, such as Dentist, GermanHero, JustAMan, Sinterklaas, That_one_nice_guy and TheGenuineSeller. The singular form implies that the vendor shop is run by a single person. This may or may not be the case. In her dissertation on Finnish company names, Paula Sjöblom (2006: 211) notes that words that refer to a single person are used as metaphors in company names, personating the company staff as a single subject (see also the concept of individualising function in Ainiala et al. 2012: 244). This can be achieved regardless of whether the company actually has one or a large number of employees. In other words, the singular form can be used to create an image of the business, rather than to share information on it.

\subsection{What images do vendors create?}

Sharing any personal information poses a possible threat for drug vendors, making them more vulnerable to interference from law enforcement authorities. A safer way to create vendor identity is to provide images that do not concern the vendor's actual characteristics. In this section, I will examine different types of images that are used in vendor names.

\subsubsection{Doctors and companies: Business images}

One common strategy in vendor names is to produce images that resemble the legal business practices in the non-virtual world. This can be attained in various ways. One option is to adopt the same vocabulary as in a real-life company and shop names. In the data, 32 names (4.2\%) include the words shop, store or market (partyshop, TheCoffeeShop, WonderlandShop, Royal_Drugstore, Dutch-store, Market24). The words company, inc and co, which are commonly used in company names, appear 13 times in the data (TheDrugCompany, crystalmethinc, DBCooper Co). The function of these names is to integrate rather than to inform. It is hardly necessary to mention that these users are specialized 
in selling items, while it turns up in their sales advertisements anyway. Business vocabulary may integrate them, at least to some extent, into legal brands and companies. This could be a beneficial strategy for the vendors, because it may make customers less aware that they are involved in illegal activity, thus making them more willing to purchase items.

Vendor names also exploit the names of well-known brands and companies. The data contain $39(5.0 \%)$ examples of these names, such as cocacola-crew, Dream_Works, LAMBORGHINI2, MonsterEnergyDrugs, starbucks101 and TESCOEXPRESS. Some brands are tightly connected to a country or known mainly on a national level (AlbertHeijn, CzechAirlines, deBijenkorf, NORWEGIANcom ${ }^{9}$ ) and thus make an indirect reference to the vendor's home country. Naturally, this type of unauthorised use of brands to gain financial benefit is a copyright violation, even though it would seem like a minor offense when compared to producing and distributing a vast amount of illegal drugs. As vendor names are not visible to a large audience, the damage caused to the reputation of brands and companies most likely remains small.

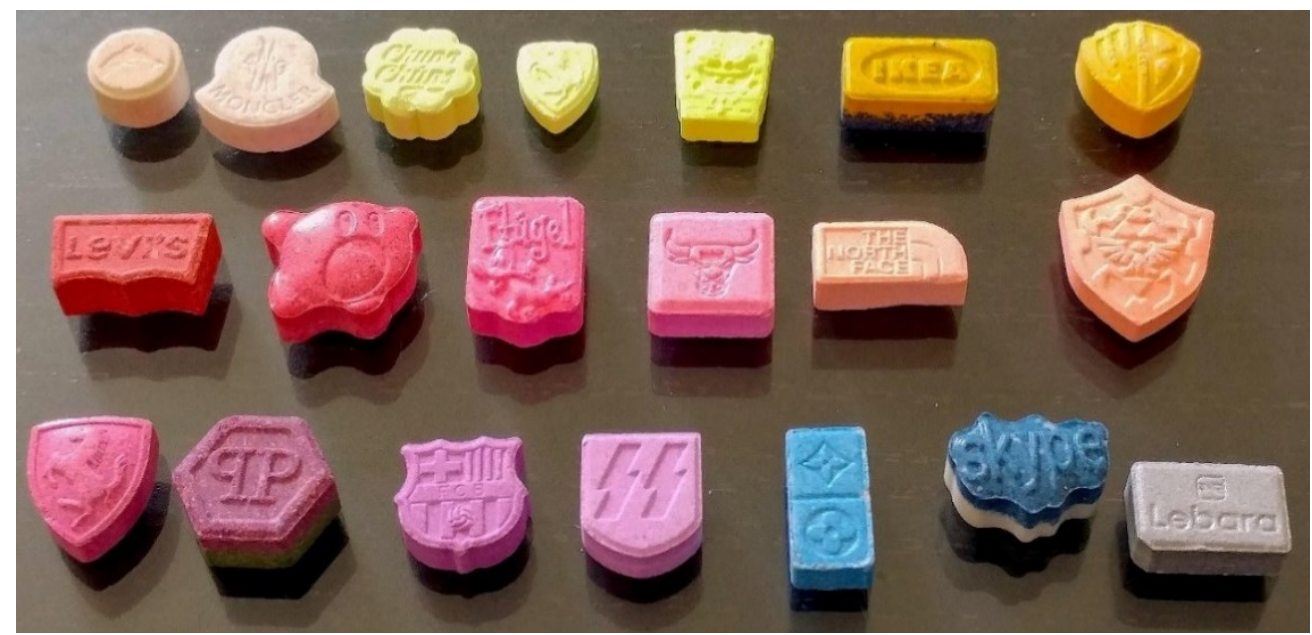

Figure 2: Ecstasy tablets with several logos, such as Warner Bros in the top right corner and Ferrari in the bottom left corner. Picture: Reddit.

Famous real-life brands are exploited not only in vendors' user names but also in the names and visual appearance of ecstasy tablets. These tablets have various shapes, and often some type of logo is printed on them (see Figure 2). In sales advertisements, tablets are named after these logos (such as $3 D$ and Flügel in Figure 1). While collecting the user names of ecstasy vendors, I also wrote down the names of the ecstasy tablets I encountered in the advertisements. I found tablets with 59 different names, most of them named after well-known international brands: Facebook, Ferrari, Hello Kitty, Louis

9 Albert Heijn and De Bijenkorf are Dutch supermarket chains. 
Vuitton, Red Bull, Rolex, Route 66, Warner Bros, Volkswagen, etc. The 59 names referred to various types of brands but especially car, food and drink brands. But why brands are used so often in ecstasy tablet names and prints? At least two reasons can be suggested. Firstly, combining reputable brands with illegal drugs creates a powerful contrast. This can be seen as a type of black humour, and it can be used in marketing the tablets. Secondly and more importantly, logo prints may help users recognise the origin of the tablet and to evaluate its quality. A common problem with ecstasy tablets, as well as with many other illegal drugs, is their varying quality. Tablets sometimes include substances that are different from what vendors claim (Tanner-Smith 2006; Vogels et al. 2009). As a consequence, some internet websites list the laboratory test results of ecstasy tablets (see for example Pillreports ${ }^{10}$ ), helping users to avoid low quality tablets. However, even the reports of laboratory tests cannot fully guarantee the product quality. Well-reputed tablets are sometimes plagiarised by other manufacturers (Duterte et al. 2009: 31-32). This accounts for the fact that tablets bearing the same logo sometimes have different contents (Giraudon \& Bello 2007). ${ }^{11}$

Real-life brand names are also used as models when creating vendor names. As examples, let us focus on the abbreviations $D r$ and $M r$. Both of these are used in many real-life brand names. For instance, $D r$ occurs in the names Dr. Oetker (food products), Dr Pepper (a carbonated soft drink) and Dr. Martens (footwear and clothing), $\mathrm{Mr}$ in the names $\mathrm{Mr}$. Clean and Mr Muscle (all-purpose cleaning supplies) and $\mathrm{Mr}$ Green (online gambling). The data contain 19 names of these types, such as DrPriority, DrRelax, dr_swiss, MrDMT, Mr_Sunshine and MrTony. The reason for using $D r$ may be that referring to a doctor creates an image of scientific expertise and this, of course, is important when manufacturing high-quality drugs. $M r$, on the other hand, is a somewhat more complex abbreviation. Drug trafficking is a predominantly male branch (UNODC 2016: 23), at least in the non-virtual world ${ }^{12}$. Thus, when names imply a vendor's gender, presumably most of these refer to males as well ${ }^{13}$. However, a few names also contain feminine references, such as

10 www.pillreports.net (accessed 2017-11-24).

11 A similar type of branding is also noticed, at least to some extent, with LSD blotters and heroin stamps (Duterte et al. 2009: 28-29). When collecting vendor name data, I encountered some famous brands, logos and prints, especially in the LSD advertisements. However, the idea of documenting them came to my mind only when examining ecstasy advertisements, so I decided to focus only on ecstasy brands in this chapter.

12 There is little evidence to suggest that this applies to users online as well, but according to Ormsby (2016: 62), most online vendors are young men.

13 On user names and gender, see Cornetto \& Nowak (2006) and Stommel (2007). Cornetto $\&$ Nowak (2006: 382) report that the user's gender can be recognised in approximately $40 \%$ of user names. 
DoctorLisa, GoddessOfGanja, MedicinalMary, Missmolly1, MsAusImports and swissprincess. Obviously, vendor names including masculine or feminine references do not necessarily divulge the actual gender of vendor(s). It is also difficult to determine whether either of them functions more successfully in marketing. DoctorLisa, which consists of a common and worldwide-known female name, was one of the most successful vendors on AlphaBay. Nonetheless, the data include few feminine references, so I am unable to draw valid conclusions as to whether or not this is purely a coincidence.

\subsubsection{Pirates and goodfellas: Criminal images}

Some vendors have adopted a marketing strategy that is contrary to the one described above; they intentionally highlight the criminality of their actions. This can also be achieved in several ways. Twenty-two names incorporate vocabulary that refers to various criminal activities, such as bandit, pirate, cartel and mafia (BrokeBandits, THIRD-EYE-PIRATE, DarkNetCartell, drugs-maffia). The pirate references may have been inspired both by internet piracy and Dread Pirate Roberts, a pseudonym used by the most famous darknet operator, Silk Road 1 creator and runner, Ross Ulbricht (Ormsby 2016: 61).

Twenty-four vendor names include references to well-known drug criminals and cartels in a real or fictional world. The names El-Patron, escobarstore and sonofpablo refer to Pablo "El Patron" Escobar, the late leader of the Colombian Medellin cartel; the names El.chapo and SinolaCartellGER to the Mexican Sinaloa cartel and its leader Joaquín Archivaldo "El Chapo" Guzman Loera; the names elpachoh and TheCaliCartel to the Colombian Cali Cartel and its late member Hélmer "Pacho" Herrera; the name KhunSa to Khun $\mathrm{Sa}$, a late opium and heroin smuggler in Myanmar; and the name CurtisCockyWarren to Curtis Warren, a British drug trafficker. In the world of fiction, vendors seem to be inspired especially by Breaking Bad, a popular and relatively recent television series dealing with the manufacturing and distribution of methamphetamine (DerHeissenberg, misterWhit3, PinkmanAndWhite ${ }^{14}$ ). Some older drug-related movies are also referred to (FRENCHCONNECTION, Scarface-Tony-Montana, The_Goodfellas 1 ). The name Dutchmalverde includes a reference to Jesús Malverde, a Robin Hood-like folklore hero in Mexican culture, celebrated particularly by drug traffickers.

Some vendor names do not refer clearly to criminality but to civil obedience and societal change (EurekaRebellion, Sons-of-Anarchy, PeoplePowerAU, NextGeneration, NewTime). In addition, the name Holden_Caulfield refers to a fictional character in J. D. Salinger's novel The Catcher in the Rye, who later have become an icon of teenage rebellion. These types of names are undoubtedly created to praise rebellion and civil obedience. They probably intend to communicate that drugs should be legal, even though this would bring the

14 The leading characters in the series are Walter "Heisenberg" White and Jesse Pinkman. 
vendors' business to an end. Previous studies have shown that many vendors sell drugs not only for revenue but also to support the libertarian ideology (e.g. Kruithof et al. 2016: 80; Munksgaard \& Demant 2016; Ormsby 2016: 66). Showing this support offers an image that these vendors are on the same side with their customers, against legislators and law enforcement.

\subsubsection{Flying and enjoying: Images of product effects}

Fifty-four vendor names $(7.1 \%$ of the data) include references to the desired effects of drugs. As ecstasy, heroin and LSD are used in rather different ways, naturally some differences can be detected between the vendors of these substances. Ecstasy and heroin are used mainly for enjoyment, relaxation or to relieve anxiety, so the names of their vendors mainly refer to positive emotions, such as happiness, enjoyment and euphoria (besafeandenjoy, happygarden, heaven-on-earth, letthegoodtimesroll, ParadiseCorner, PerpetualEuphoria, Timetofiesta). LSD, on the other hand, is often used for meditative or spiritual purposes, and therefore some vendor names refer to the human mind and its activities (georgejacobjung, Neuropolis, Psyche, Psychonauta01). Some names also advertise excitement by creating images of flying and adventure (DutchFLY, Heavenadventure, SeeBuyFly,), sometimes even in cosmic spheres (AncientAstronaut, Cosmic_Consciousness, Triptotheuniverse).

It is hardly surprising that almost no vendor names refer to the adverse effects of drug use, such as dependency, overdoses or "bad trips". Perhaps the only name of this type in the data is strung-out, referring to one suffering from withdrawal symptoms. Even though previous studies suggest that both cryptomarket vendors and purchasers are highly aware of the possible risks of using drugs (van Hout \& Bingham 2014; Bancroft \& Reid 2016), it is obviously not in vendors' interest to highlight them.

\subsubsection{Fast and safe: Images of the quality of services}

Sixty-five names $(8.5 \%$ of the data) refer to the quality of the vendor's services. Some names refer to the high quality of the products (AmsterdamLiquidXno1, BestDutchStuff, DutchQualityTrips, LabTested, PeRfecT_ProDuctS, Quality_Opiates). This kind of references could be problematic, as the concept of quality can be understood in many ways. Bancroft \& Reid (2016) suggest that for cryptomarket users, quality could mean reliability, purity, potency, or the predictability of the drug effect. Some names convey the delivery of the products being fast (ChemExpress, FastGermanDealers) and safe (SafeSecureWorldwide, StealthMasters ${ }^{15}$ ). Some names express the high quality

15 The word stealth is commonly used in cryptomarkets when discussing packing methods. It means that the drugs are not easily recognised by customs officers or mail carriers. 
of the vendor shop without specifying any particular reason (DutchElite, GermanMasters, HarddrugsSpecialist, theprofessionals).

In addition to those 65 names, many vendor names include vocabulary that evoke images of luxury and dignity, such as king, prince, lord, boss, star, palace or golden (ChemicalAllstars, Dopelord, EtiKing, funstar69, GermanDrugPalace, goldendrugs, LordChem, NarcoBoss, shromprince, XTC-Kingdom). A similar phenomenon occurs in real-life commercial names, such as Burger King, Dairy Queen or Starbucks. These names may suggest indirectly that those vendors are of a higher class than the others, but at least in vendor names, references to high quality must be interpreted images rather than actual information. A vendor may actually have a special expertise concerning one or more sectors of the drug business, such as the quality of product or the shipping process being fast and safe. Yet the customer needs to estimate vendor quality based on their feedback rather than what they claim themselves.

\subsubsection{Images not related to drugs or business}

In addition to the groups introduced above, a large number of vendor names are not related to drugs or business. This group consists of 252 names (33.1\% of the data) and it is highly heterogeneous. The meaning of most of these names are transparent (digitalpunk, IGotJohns, instrument, LittleCaesar, Mantikor, redlemon17, this_fading_light, topgun2, YourMomsBox). There are some references to fictional characters (such as CarterPewterschmidt, dionysos, Doug-Heffernan, DrMantisTobogganMD, gandalfsgear, Kaonashi, Obelix.0.7, SamSpade2, .Shinigami.) and also real persons (howardstern101, Sinatra, ursmeier), but noticeably less than in the clearweb user names (cf. Hämäläinen 2019). There are also 40 names $(5.2 \%$ of the data) that I have interpreted as quasi-language (a term adapted from Ainiala et al. 2012: 239), expressions that do not convey meaning in any known language ( $d k b v$, gir601, hommpi, sdhall, slza, ysllim). These also constitute a smaller number than reported in previous studies (Hämäläinen 2013: 217-218; 2019).

Perhaps it is surprising that the data include this large number of vendor names that do not have any visible connection to a vendor's business. For the clearweb, this could easily be explained by the fact that many web users do not consider user names to be important and therefore do not expend time thinking about them. For a large-scale drug business, however, this type of indifference would be surprising. User name offers the vendor a good opportunity to share information and create tempting images; not using this opportunity amounts to not exploiting all the marketing potential. The most successful vendors are able to make millions of dollars a year, so a name can make a big financial difference. However, it is possible that the vendors try to avoid excessively branding themselves. If they make themselves famous on the darknet, they also face a higher risk of being apprehended by law enforcement officials. With limited resources, the police often centralise their force to chase the most 
visible and large-scale operators in the drug markets. The vendor Douppikauppa, introduced in the Data section, almost created a monopoly in Finnish online drug market by receiving media attention through interviews, but was later arrested after an extensive police operation.

On the other hand, it is important to notice that the percentage of user names related to the topic of the website is far higher on AlphaBay (67\%) than in the clearweb communities examined in previous studies ${ }^{16}$. In addition to the commercial significance of vendor names, this difference between AlphaBay and clearweb communities is due to the fact that on the clearweb, many people use the same user names in several communities, regardless of the theme of each community. Darknet vendors, on the other hand, cannot use the same name as they do on the clearweb, as this could reveal their identity. Instead, they must devise a new user name for their vendor account, and an obvious inspiration for the name could be the theme of the website. In this sense, vendor names are perhaps closer to real-life company names, which often include at least some type of reference to the company's branch, owner, etc.

Table 2: Summary of the different types of information and images that occur in vendor names

\begin{tabular}{|r|c|c|}
\hline Type & Count & \% \\
\hline Product & 124 & 16.3 \\
\hline Country of origin & 146 & 19.2 \\
\hline Number of employees & 71 & 9.3 \\
\hline Business images & 100 & 13.1 \\
\hline Criminal images & 53 & 7.0 \\
\hline Product effects & 57 & 7.5 \\
\hline Quality of services & 65 & 8.5 \\
\hline Images not related to drugs & 258 & 33.9 \\
\hline
\end{tabular}

To summarise the analysis, Table 2 lists the distribution of the different types of information and images presented in AlphaBay vendor names ${ }^{17}$. It must also be mentioned that the concepts of information and image are not completely separate, even though they are examined in separate sections in this article. The two categories partially overlap. Some names clearly belong to either group; the vendor DrugsFromHolland most likely is originally from the

16 To cite some examples from Finnish websites, in the football-themed discussion forum FutisForum, approximately $20 \%$ of the user names are related to football, in a Harry Potter fanfiction community, approximately $10 \%$ of the user names are related to Harry Potter books or films, and in the online gaming website Playforia, less than $1 \%$ of the names are connected to video games (Hämäläinen 2016: 409-410).

17 When reading the table, it is important to note that a name can simultaneously belong to more than one of the groups. For example, the name CocaColaFR includes both a business image (using a real-life brand name) and a reference to the country of origin. Therefore, the total count of different types (874) slightly exceeds the number of names in the data (762). 
Netherlands (information), while the vendor MonsterEnergyDrugs most likely has nothing to do with the energy drink or its producer (image). Some instances are not that clear. Names such as FastGermanDealers or TheTechnoCrew could as easily be owned by a group of people as by a single person who attempts to create an image of a group working together. And names referring to the high quality of products and service, such as Quality_Opiates and StealthMasters, might provide true information on the vendors' business but they could as easily merely allure customers with exaggerated images. Without interviewing vendors or examining their actions more closely, the category that their names belong to cannot be determined accurately. This means that one must estimate which option is the most likely. Despite these difficulties, I wanted to present these categories separately in order to highlight some overall tendencies that are visible in the data. I hope this has not been too confusing.

\section{Conclusion}

Illegal drugs have begun to change owners online. Deals are made on darknet cryptomarkets, where vendors are known solely by their user names. With their great financial significance, vendor names offer new perspectives for user name studies. In this article, three main research questions have been examined: what are the features of the structure and orthography of vendor names, what information do vendors share and what type of images they create in their names? Nevertheless, the fourth question presented in the introduction remains unsolved: are vendor names closer to clearweb user names or names of companies and brands?

On average, vendor names are longer than clearweb user names but distinctly shorter and simpler than company names. Typically for user names, vendor names use numbers, special characters and orthographic variation, but less frequently than in clearweb communities. Many vendors share information on the product they are selling, their home country and whether they work as a single agent or as a group. Vendors also create various types of images in their names. Many of them attempt to integrate their activities into normal legal business by adopting similar vocabulary and naming models or even by plagiarising the names of well-known brands. In contrast, a somewhat smaller group of vendors intentionally highlight their criminality by using names of infamous real-life or fictional drug offenders, or vocabulary referring to illegal activities or civil obedience. Some vendors also create positive images of the effects of their products or the quality of their services. These informative references to a vendor's business as well as persuasive and integrative images are typical for commercial names, especially company names (Ainiala et al. 2012: 243-244). Many vendor names are, however, not related to drugs or to the drug business in any visible way. Those names mostly resemble user names 
in clearweb communities. All things considered, user names of the darknet drug vendors perhaps resemble more closely other user names than real-life commercial names, yet the commercial names have also considerably influenced vendor names.

Cryptomarket AlphaBay, the data source for this study, is no longer operating and its alleged founder is dead (Deepdotweb 2017b). Cryptomarkets as a phenomenon, however, are not likely to disappear. Previous shutdowns of prominent cryptomarkets have caused temporary disruptions to the online drug trade, but new marketplaces have promptly risen to replace the closed ones (Décary-Hétu \& Giommoni 2017; van Buskirk et al. 2017). When compared to traditional drug trafficking, cryptomarkets have both advantages and disadvantages. For many people, cryptomarkets lower the threshold for trying illegal drugs, therefore increasing the number of users and also health-related and social risks. On the other hand, cryptomarkets are found to decrease drugrelated violence and to improve the substance quality, which reduce the harm to users (Barratt, Ferris \& Winstock 2016; Caudevilla et al. 2016; Aldridge, Stevens \& Barratt 2017).

For scholars, cryptomarkets are a valuable source of data. Large volumes of information can be collected with little effort and without being in contact with organised criminality. In the near future, we can expect to receive an increasing amount of new information on drug markets, which helps us understand these phenomena better and prevent the harms they cause to individuals and society.

\section{References}

Ainiala, Terhi \& Saarelma, Minna \& Sjöblom, Paula. 2012. Names in focus: An introduction to Finnish onomastics. Helsinki: Finnish Literature Society.

Aldridge, Judith \& Décary-Hétu, David. 2014. Not an 'Ebay for Drugs': The Cryptomarket 'Silk Road' as a Paradigm Shifting Criminal Innovation. Social Science Research Network (SSRN). (http://dx.doi.org/10.2139/ ssrn.2436643) (Accessed 2018-04-24.)

Aldridge, Judith \& Askew, Rebecca. 2017. Delivery dilemmas: How drug cryptomarket users identify and seek to reduce their risk of detection by law enforcement. International Journal of Drug Policy 41, 101-109.

Aldridge, Judith \& Stevens, Alex \& Barratt, Monica J. 2017. Will growth in cryptomarket drug buying increase the harms of illicit drugs? Addiction 113, 789-796.

Aleksiejuk, Katarzyna. 2014. Internet names as an onomastic category. In Names in daily life: Proceedings of the XXIV International Congress of Onomastic Sciences, 243-255. Barcelona: Generalitat de Catalunya. 
Aleksiejuk, Katarzyna. 2016a. Pseudonyms. In Hough, Carole (ed.), Oxford handbook of names and naming, 438-452. Oxford: Oxford University Press.

Aleksiejuk, Katarzyna. 2016b. Internet personal naming practices and trends in scholarly approaches. In Puzey, Guy \& Laura Kostanski (eds.), Names and naming: People, places, perceptions and power, 3-17. Bristol: Multilingual Matters.

Aleksiejuk, Katarzyna. 2017. Names on the Internet: Towards electronic socio-onom@stics. University of Edinburgh.

Alphabaymarket.com. 2017. AlphaBay Reportedly Seized by Authorities. (https://alphabaymarket.com/alphabay-seized/) (Accessed 2018-04-24.)

Bancroft, Angus \& Reid, Peter Scott. 2016. Concepts of illicit drug quality among darknet market users: Purity, embodied experience, craft and chemical knowledge. International Journal of Drug Policy 35, 42-49.

Barratt, Monica J. 2012. Silk Road: eBay for drugs. Addiction 107, 683.

Barratt, Monica J. \& Aldridge, Judith. 2016. Everything you always wanted to know about drug cryptomarkets (but were afraid to ask). International Journal of Drug Policy 35, 1-6.

Barratt, Monica J. \& Ferris, Jason A. \& Winstock, Adam R. 2016. Safer scoring? Cryptomarkets, social supply and drug market violence. International Journal of Drug Policy 35, 24-31.

Bartlett, Jamie. 2014. The dark net. Inside the Digital Underworld. Random House.

Bechar-Israeli, Haya. 1995. From $<$ Bonehead $>$ to $<$ cLoNehEAd $>$ : Nicknames, play and identity on Internet Relay Chat. Journal of Computer-Mediated Communication 1.

Buxton, Julia \& Bingham, Tim. 2015. The rise and challenge of dark net drug markets. Global Drug Policy Observatory, Swansea University, Policy brief 7. (http://www.drugsandalcohol.ie/23274/1/Darknet\%20Markets.pdf) (Accessed 2018-04-24.)

Caudevilla, Fernando \& Ventura, Mireia \& Fornís, Iván \& Barratt, Monica J. \& Vidal, Claudio \& lladanosa, Cristina Gil \& Quintana, Pol \& Muñoz, Ana \& Calzada, Nuria. 2016. Results of an international drug testing service for cryptomarket users. International Journal of Drug Policy 35, 38-41.

Christin, Nicolas. 2013. Traveling the Silk Road: A measurement analysis of a large anonymous online marketplace. In Proceedings of the 22nd international conference on World Wide Web, 213-224.

Cornetto, Karen M. \& Nowak, Kristine L. 2006. Utilizing usernames for sex categorization in computer-mediated communication: Examining perceptions and accuracy. CyberPsychology \& Behavior 9(4), 377-387.

Décary-Hétu, David \& Leppänen, Anna. 2013. Criminals and signals: An assessment of criminal performance in the carding underworld. Security Journal 29(3), 442-460. 
Décary-Hétu, David \& Giommoni, L. 2017. Do police crackdowns disrupt drug cryptomarkets? A longitudinal analysis of the effects of Operation Onymous. Crime, Law and Social Change 67(1), 55-75.

Décary-Hétu, David \& Quessy-Doré, Olivier. 2017. Are repeat buyers in cryptomarkets loyal customers? Repeat business between dyads of cryptomarket vendors and users. American Behavioral Scientist 61(11), $1341-1357$.

Deepdotweb. 2015a. 2014 in the dark net markets: By the numbers. (https://www.deepdotweb.com/2015/01/03/2014-in-the-dark-net-marketsby-the-numbers/) (Accessed 2018-04-24.)

Deepdotweb. 2015b. Alphabay market has reached 200,000 users. (https://www.deepdotweb.com/2015/10/14/alphabay-market-has-reached200000-users/) (Accessed 2018-04-24.)

Deepdotweb. 2016. How Scandinavia's biggest vendor created his empire on Valhalla. (https://www.deepdotweb.com/2016/02/01/how-scandinavias-biggestvendor-created-his-empire-on-valhalla) (Accessed 2018-04-24.)

Deepdotweb. 2017a. German police place "trial" orders at AlphaBay sellers to track criminals. (https://www.deepdotweb.com/2017/04/26/german-police-placetrial-orders-alphabay-sellers-track-criminals/) (Accessed 2018-04-24.)

Deepdotweb. 2017b. Alleged Alphabay admin found dead in Bangkok jail. (https://www.deepdotweb.com/2017/07/14/alleged-alphabay-admin-founddead-bangkok-jail/) (Accessed 2018-04-24.)

Deepdotweb. 2017c. A globally coordinated operation just took down Alphabay and Hansa. (https://www.deepdotweb.com/2017/07/20/globally-coordinatedoperation-just-took-alphabay-hansa/) (Accessed 2018-04-24.)

Dingledine, Roger \& Mathewson, Nick \& Syverson, Paul. 2004. Tor: The second-generation onion router. Naval Research Lab Washington DC.

Dolliver, Diana S. \& Kenney, Jennifer L. 2016. Characteristics of drug vendors on the Tor network: A cryptomarket comparison. Victims \& Offenders 11, 600-620.

Duterte, Micheline \& Jacinto, Camille \& Sales, Paloma \& Murphy, Sheigla. 2009. What's in a label? Ecstasy sellers' perceptions of pill brands. Journal of Psychoactive Drugs 41(1), 27-37.

Ecker, Robert. 2011. Creation of Internet Relay Chat nicknames and their usage in English chatroom discourse. Linguistik Online 50(6), 3-29.

EMCDDA. 2013. European Union drug markets report: A strategic analysis. European Monitoring Centre for Drugs and Drug Addiction. Lisbon.

Giraudon, Isabelle \& Bello, Pierre-Yves. 2007. Monitoring ecstasy content in France: results from the National Surveillance System 1999-2004. Substance Use \& Misuse 42(10), 1567-1578. 
Hardy, Robert Augustus, \& Norgaard, Julia R. 2016. Reputation in the Internet black market: An empirical and theoretical analysis of the Deep Web. Journal of Institutional Economics 12(3), 515-539.

Hassa, Samira. 2012. Projecting, exposing, revealing self in the digital world: Usernames as a social practice in a Moroccan chatroom. Names 60(4), 201-209.

Hämäläinen, Lasse. 2013. User names in the Online Gaming Community Playforia. In Sjöblom, Paula \& Ainiala, Terhi \& Hakala, Ulla (eds.), Names in the economy: Cultural prospects, 214-229. Newcastle: Cambridge Scholars Press.

Hämäläinen, Lasse. 2016. Suomalaisten verkkoyhteisöjen käyttäjänimet [User names in Finnish online communities]. Virittäjä 120, 398-422.

Hämäläinen, Lasse. 2019 (in press). User names in Finnish online communities. Studia Anthroponymica Scandinavica 35.

Kelley, James B. 2012. Gay naming in online gaming. Names 60(4), 193-200.

Kokkinakis, Athanasios V. \& Lin, Jeff \& Pavlas, Davin \& Wade, Alex R. 2016. What's in a name? Ages and names predict the valence of social interactions in a massive online game. Computers in Human Behavior 55, 605-613.

Kruithof, Kristy \& Aldridge, Judith \& Décary-Hétu, David \& Sim, Megan \& Dujso, Elma \& Hoorens, Stijn. 2016. Internet-facilitated drugs trade: An analysis of the size, scope and the role of the Netherlands. WODC, Ministerie van Veiligheid en Justitie. (https://www.rand.org/pubs/ research_reports/RR1607.html) (Accessed 2018-04-24.)

Martin, James. 2014. Drugs on the dark net: How cryptomarkets are transforming the global trade in illicit drugs. Springer.

Martin, James, \& Christin, Nicolas. 2016. Ethics in cryptomarket research. International Journal of Drug Policy 35, 84-91.

Munksgaard, Rasmus \& Demant, Jakob. 2016. Mixing politics and crime: The prevalence and decline of political discourse on the cryptomarket. International Journal of Drug Policy 35, 77-83.

Nuessel, Frank. 2017. A note on selected names of Colorado medical marijuana dispensaries. Names 65(2), 112-120.

Nurmi, Juha \& Kaskela, Teemu \& Perälä, Jussi \& Oksanen, Atte. 2017. Seller's reputation and capacity on the illicit drug markets: 11-month study on the Finnish version of the Silk Road. Drug \& Alcohol Dependence 178, 201-207.

Ormsby, Eileen. 2016. Silk Road: insights from interviews with users and vendors. In The Internet and drug markets, 61-68. Lisbon: EMCDDA.

Sjöblom, Paula. 2006. Toiminimen toimenkuva: suomalaisen yritysnimistön rakenne ja funktiot [A firm name's job description: the structure and functions of Finnish company names]. Helsinki: Finnish Literature Society. (Finnish Literature Society Publications 1064.) 
Sjöblom, Paula. 2016. Commercial names. In Hough, Carole (ed.), Oxford handbook of names and naming, 453-464. Oxford: Oxford University Press.

Stommel, Wyke. 2007. Mein Nick bin ich! Nicknames in a German forum on eating disorders. Journal of Computer-Mediated Communication 13, 141 162.

Tanner-Smith, Emily E. 2006. Pharmacological content of tablets sold as "ecstasy": Results from an online testing service. Drug and Alcohol Dependence 83(3), 247-254.

Tzanetakis, Meropi \& Kamphausen, Gerrit \& Werse, Bernd \& von Laufenberg, Roger. 2016. The transparency paradox: Building trust, resolving disputes and optimising logistics on conventional and online drugs markets. International Journal of Drug Policy 35, 58-68.

UNODC. 2016. World Drug Report 2016. United Nations Office on Drugs and Crime.

Van Buskirk, Joe \& Naicker, Sundresan \& Roxburgh, Amanda \& Bruno, Raimondo \& Burns, Lucinda. 2016a. Who sells what? Country specific differences in substance availability on the Agora cryptomarket. International Journal of Drug Policy 35, 16-23.

Van Buskirk, Joe \& Naicker, Sundresan \& Bruno, Raimondo. \& Burns, Lucinda \& Breen, C. \& Roxburgh, Amanda. 2016b. Drugs and the Internet 7. (https://ndarc.med.unsw.edu.au/sites/default/files/ndarc/resources/dnetbull etin_issue7_final.pdf) (Accessed 2018-04-24.)

Van Buskirk, Joe \& Bruno, Raimondo \& Dobbins, Timothy \& Breen, Courtney \& Burns, Lucinda \& Naicker, Sundresan \& Roxburgh, Amanda. 2017. The recovery of online drug markets following law enforcement and other disruptions. Drug and Alcohol Dependence 173, 159-162.

Van Hout, Marie Claire \& Bingham, Tim. 2014. Responsible vendors, intelligent consumers: Silk Road, the online revolution in drug trading. International Journal of Drug Policy 25, 183-189.

Visakko, Tomi. 2015. Self-promotion as semiotic behavior: The mediation of personhood in light of Finnish online dating advertisements. Helsinki: University of Helsinki. (http://urn.fi/URN:ISBN:978-951-51-1399-3) (Accessed 2018-04-24.)

Vogels, N. \& Brunt, T. M. \& Rigter, S. \& Van Dijk, P. \& Vervaeke, H. \& Niesink, R. J. 2009. Content of ecstasy in the Netherlands: 1993-2008. Addiction 104(12), 2057-2066. 